\title{
CYLINDRICAL LASER TARGETS
}

J. A. Rinde

Prepared for U.S. Energy Research \& Development

Administration under contract No. W-7405-Eng-48
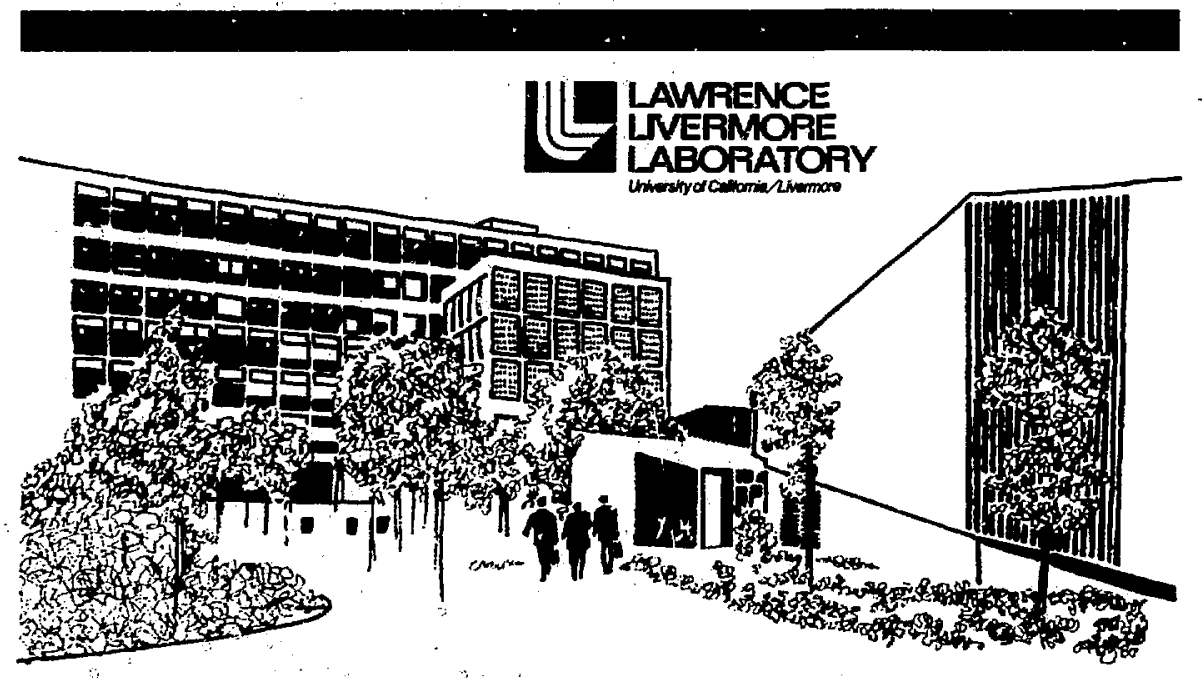

June 5, 1975

\section{MASTER}


NOTICE

"This.report was preparet as an account of work sponsored by the United States Government. Neither the United States nor the United States Energy Reremeh Detelopment Administration, nor any of their employees, nor any of their contractors. subcontractors, or their employees, makes any werresty, express or implied, or assumes any legal liebility or responsibility for the accuracy. completencss or usefulnes of any information, apperatus, product or process disclosed, or represents that. its use would not intringe privately-owned riphts"

Printed in the United States of America Available from

National Technical Information Service $\mathrm{U}, \mathrm{S}$. Department of Commerce 5285 Port Royal Road Springfield, Virginia 22151

Price: Printed Copy $\$$ *; Microfiche $\$ 2.25$

$$
\begin{gathered}
{ }^{*} \text { Pages } \\
\hline 1-50 \\
51-150 \\
151-325 \\
326-500 \\
501-1000
\end{gathered}
$$

NTIS

Selling Price

$\$ 4.00$

$\$ 5.45$

$\$ 7.60$

$\$ 10.60$

$\$ 13.60$ 


\title{
近 \\ LAWRENCE LMEAMORE LABOAATOFY

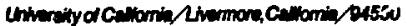

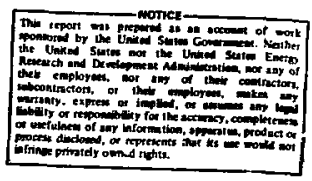

UCRL-51787

\section{CYLINDRICAL LASER TARGETS}

\author{
J. A. Rinde
}

MS, date: June 5, 1975 


\begin{abstract}
This report summarizes the work to date on cylindrical laser targets and describes the requirements, methods of preparation, and the results achieved on the initial prototypes.
\end{abstract}

\title{
Introduction
}

Cylindrical targets are one member of a series of acceleration targets that consist of thin sheets, cylinders, and spherical shells. Their purpose is to mock up the implosion characteristics of a thin bare shell of DT. All these targets have a radius-to-thickness ra.io of approximately 30 to 1 , and may be subject to Taylor instabilities. As a result the surface finish tolerances are extremely high and have been the controlling variable in determining the $\mathrm{m} r . \mathrm{d}$ of production of these cylindrical targets.
To achieve high surface finishes we have used a unique diamond turning machine available at LLL.* The process for making cylinders consists of machining cylind rical copper mandrel, vapor plating on a thin coat of aluminum or plastic, machining the outside surface, cutting the cylinders to length and dissolving out the copper.

*J. Bryan, R. Clouser, and E. Holland, Am. Machinist Ill (25) 149 (1967).

\section{Cylinder Requirements}

The overall requirements for the cylindrical laser targets are:

- Low $\mathbf{Z}$ to simulate DT.

- Transparent or reflecting to survive the longterm precursor.

- Surface finish tolerance - both inside and outside surfaces:

$$
\text { for } \lambda \gg 2 \pi d, \Delta(\rho \mathrm{d})<\frac{\rho d}{10} ; \Delta d<\frac{d}{10}
$$

$$
\text { for } \lambda \ll 2 \pi \mathrm{d}, \Delta(\rho \mathrm{d})<\mid \mu \mathrm{g} / \mathrm{cm}^{2}
$$$$
\Delta \mathrm{d}<10 \mathrm{~nm}
$$

where $\lambda=$ wavelength; $\rho=$ density and $\mathrm{d}=$ thickness.

- Dimensions:

$$
\begin{array}{lr}
\text { length } & 500-1000 \mu \mathrm{m} \\
\text { radius } & 250-500 \mu \mathrm{m} \\
\text { thickness } & 2-15 \mu \mathrm{m}
\end{array}
$$

- Conformity to cylindrical shape $\pm 10 \%$. 


\section{Fabrication}

\section{FABRICATION OF ALUMINUM CYLINDERS}

This section describes a procedure for the construction of hollow cylinders of high-purity aluminum that are $500 \mu \mathrm{m}$ in diameter and $500 \mu \mathrm{m}$ in length, with a $25-\mu \mathrm{m}$ wall thickness. The most restrictive requirement is that the cylinders have surface finishes on both the inside and outside surfaces of $10 \mathrm{~nm}$ or better. To meet this requirement, it was decided to machine a mandrel to tolerance and then vapor plate it with aluminum to replicate the mandrel surface on the inside of the aluminum cylinder. The outside surface of this aluminum-coated mandrel was then machined to size and to a high surface tolerance. The choice of suitable metals is limited by considerations of atomic number, the ability to be machined to a high surface finish, and the relative solubility-insolubility of any given pair of metals to a given solvent. Out of these constraints we chose OFHC copper for the mandrel metal and aluminum for the cylinder metal, the solvent being $\mathbf{7 0 \%}$ nitric acid.

Figure 1 represents the copper mandrel after final machining and before vapor plating. Mandrels are 3.2 $\mathrm{cm}$ long and $6.3 \mathrm{~mm}$ in diameter over most of this length, taper'ing down on a $45^{\circ}$ angle to a $500-\mu m$-diam section $3 \mathrm{~mm}$ long. The 6-mm-diam section is used to hold the copper mandrel in the lathe and also servcs as a reference surface for recentering the mandrel in the lathe after it has been vapor plated. The $500-\mu \mathrm{m}$ diam section is machined to a high surface finish as is a short length of the 6-mm section, for referencing. After the $500-\mu \mathrm{m}$-diam section has been vapor plated with aluminum the mandrel is put back into the lathe, recentered and the outside surface of the coated cylinder, now about $600 \mu \mathrm{m}$ in diameter, is machined down to a final diameter of $550 \mu \mathrm{m}$. Using a tool with a $50^{\circ}$ included angle, the $3-\mathrm{mm}-\mathrm{long}$ cylinder is grooved at $500-\mu \mathrm{m}$ intervals through the aluminum layer and into the copper mandrel. Figure 2 is a photograph of one of these mandrels after the above steps, showing that four cylinders can be obtained from one of these mandrels. Several mandrels were produced in our initial run and the copper dissolved out in nitric acid to produce cylinders. The two finished cylinders with good surfaces are shown in Fig. 3.

Results from the copper dissolving step were mixed, with cylinders from one mandrel having a good surface finish and those from another showing definite areas

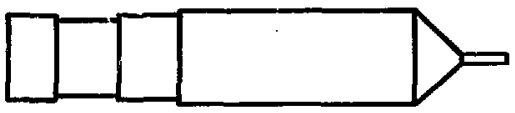

Fig. 1 Copper mandrel, $3.2 \mathrm{~cm}$ long.

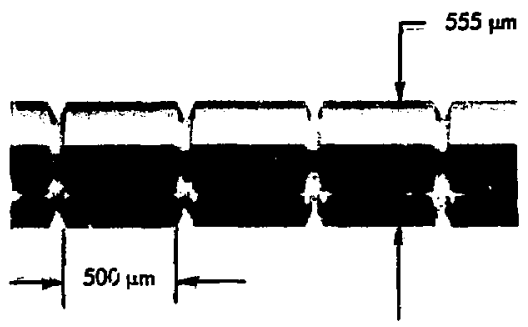

Fig. 2 Aluminum-costed copper mandrel after machining.

of etching. In the first case, where a good surface was produced, pure $70 \%$ nitric acid completely dissolved the copper in $25 \mathrm{~min}$. In this case, only the aluminum cylinders and part of the tapered section of the copper mandrel were dipped into the nitric acid. The copper dissolved out of the end cylinder first, and it fell off. followed in order by cylinders number 2,3 , and 4 .

The conditions that produced the etched aluminum cylinders were different in two respects. First, the nitric acid was diluted to $60 \%$ to increase the rate of dissolution. Second, the entire copper pin was placed in the nitric acid solution. Whether these clianges were the cause of the etching is unknown, but it is clear that more experimentation is required. However, we have demonstrated that aluminum cylinders with good surface finishes are possible, even if the exact conditions may not be fully known. 

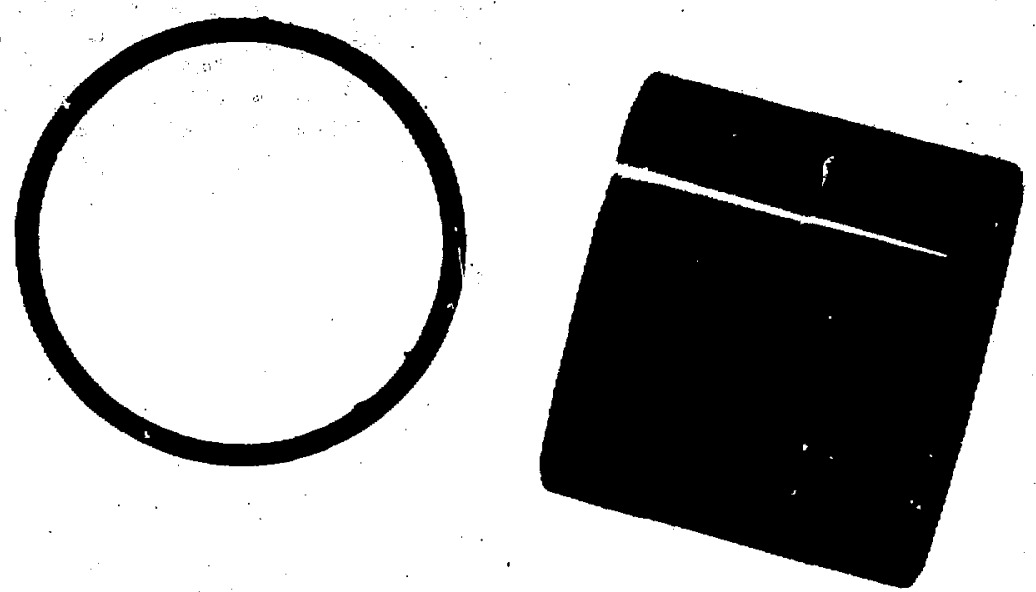

Fig. 3 Aluminum cylinders $500 \mu \mathrm{m}$ long with high surface finisls.

Another problem witt the surface finish is the inside surface of the cylinder. One cylinder was cut in half and the inside surface of the aluminum examined under a microscope. We found that the aluminum surface had not replicated the copper mandrel. j.t. its surface structure had a grain size of $1-2 \mu \mathrm{m}$. There are several possible retsons for this failure to replicalte. one of them being the geometry, and these are curently under investigation.

\section{FABRICATION OF PLASTIC CYLINDERS}

Plastic cylinders of parylene (poly-para-xylene) have been made using the same technique described above for the aluminum cylinders. Figure 4 shows one of these cylinders resting on a stage micrometer. The photo shows the high level of transparency of the plastic and also the high surface finish. Dimensions of the cylinders are $500 \mu \mathrm{m}$ i.d. by $500 \mu \mathrm{m}$ long with a wall thickness of about $70 \mu \mathrm{m}$.

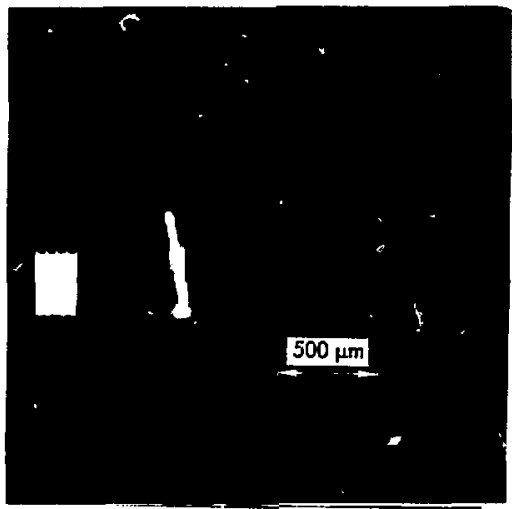

Fig. 4 Paryline cylinder $500 \mu \mathrm{m}$ long with high surface finisl. 
These cylinders were produced to determine 'the quality of surface rinish obtainable on machined parylene cylinders. Because of this no altempt was marle to achieve a thinner wall. We expect that wall thicknesses down to several micrometers should present no significant problems.

It would be desinabie to eliminate the need to dissolve the mandrel in nitric acid, which reacts with some plastics. This migit be done by giving the mandrel a very thin vapor-deposited coat of sodium chloride to act as a rejease agent. The parylene or other plastic layer would be deposited from the vapor state or by a plasma deposition technique. After machining to a smooth outer surface the whole assembly would be soaked in water to dissolve the sodium chloride, freeing the plastic eyllinders.

\section{Surface Finish Data}

Three separate methods have been used to evaluate the finish of the machined metal and plastic surfaces. These are direct contact, the transmission electron microscope (TEM) and a scanning electron micto:cope (SEM).

In our initial attempt al machining $500-\mu \mathrm{m}-\mathrm{diam}$ copper mandrels to a high finish, we made a group of ten and measured the surface roughness by direct contuct. The instrument, calked a Taly.step, drags a 0.1$x-3-\mu m$ foot over the surface and measures the displace ments. Of the ten copper mandreis measured, one had a surface rouphness of $\pm 10 \mathrm{~nm}$ over n.ost of the area with the worst peaks being within $\pm 12.5 \mathrm{~nm}$. Figure 5 shows part of the Taly-step Irace for this mandrel. All rine of the other mandrels had surface roughness of less than $\pm 20 \mathrm{~nm}$ with a few spikes as high as $\pm 35 \mathrm{~nm}$. Since this was the first attempt at matching these surfaces, it saems izasonable to expect surface fougli: .ess of $\pm 10 \mathrm{~nm}$ to be achieved on s production basis.
To check the Taly-step results we used the TEM in a somewhat unorthodox way. In this method, wit cut the 500-jim-diam section used in Fig. 5 off one of the copper mandrels so that it would fit on a normal TEN vrid. Focusing the TEM on the waist of the cylinder produced a good shadow graph of the suiface. Photographs taken in this way are shown in Fig. 6. The photograph at a magnification $10,000 \times(10 K)$ shows an area $6 \mu \mathrm{m}$ long. In this length, the surface roughness is within $\pm 10 \mathrm{~nm}$. The other photograplis at 40 . $80 \mathrm{~K}$ show surface roughness of less than $\pm 15 \mathrm{~nm}$. therefore verifying the Taly-step measurements. We do not expect a mp-to-one correspondence of these measurements since different areas were measured. The photographs at 60 and at $80 \mathrm{~K}$ show grooves with spacings of $0.2-0.4 \mu \mathrm{m}$ apant, i.e. the tool marks from the machining of watior.

The scanning electron microscope was used to examine large surface areas in a qualitative way for

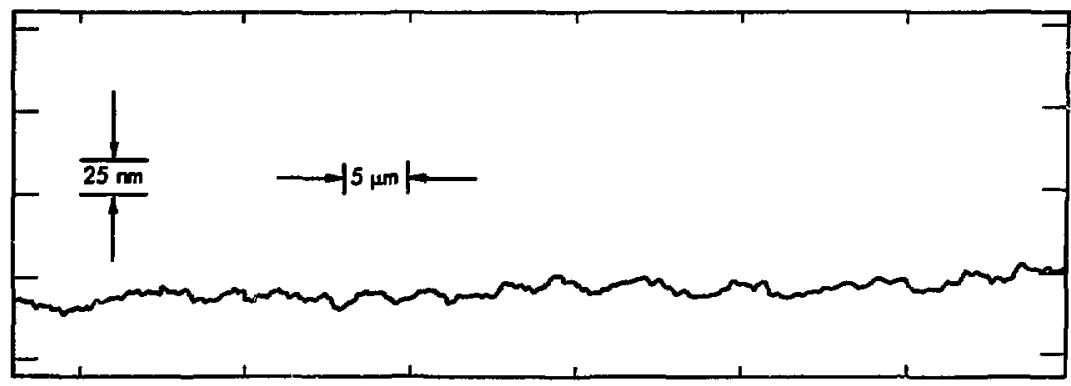

Fig. 5 Taly-step trace of copper mandrel surface. 


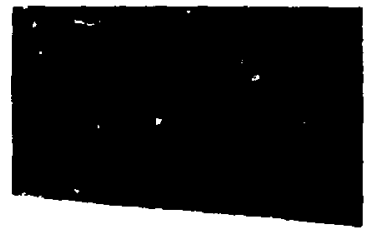

$10,000 \times$

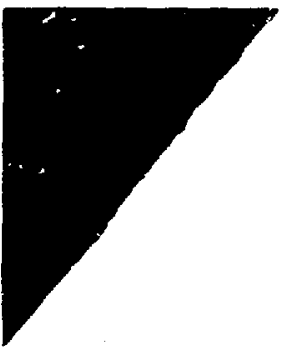

$40,000 x$

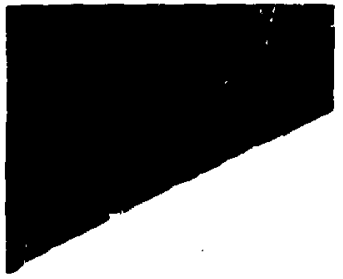

$40,000 \times$

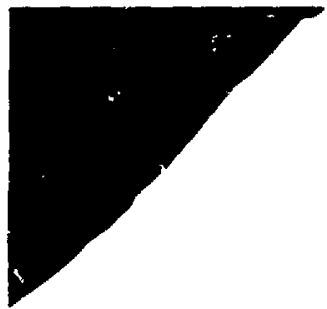

$60,000 \times$

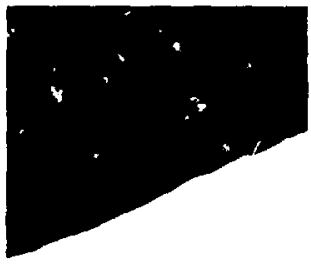

$40,000 \times$

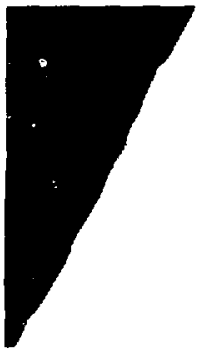

$80,000 \times$

Fig. 6 Shalowgruphs of 500-pm-diam copper cylinder surface.

tool marks and gross suriate imperfections. Figure 7 is a good exaniple of what can bit sten using the SEM. This ploto sllows all area at jo0nX where there are thret stratthes that were sten at $100 \times$ using an opticil microsicope. Fxamination of Fig. 7 strows that these stratches are not the result of the machining, but are from some other source. The mathine marks can be $x^{2}{ }^{2}=$ in the background and an' spaced $0.2-0.4 \mu \mathrm{m}$ apart, as was shown in the TEM results in Fig. 6. The SEM photo gives a goou measure of this spacing but not of their depth. This was better shown by the TEM shadow graplss.

The surface finish lids been measured on three 500 um-i.d. parylente cylinders using the Taly-step. Surface finishes of $\pm 30 \mathrm{~nm}$ and \pm 50 nin were acticued on two cylinders maclined on the same day and \pm 125 $\mathrm{nm}$ paik-to-peak on another cylinder mashined previously. All three were mide on the same equipment used to produce titc aluminum cylinders. Only the radius of the diamond bit was varied: a $25 \mu \mathrm{m}$ radius produced the best surface finishes.

The parylene cylinder with the best surface finish was axamined using the SEM. Figure 8 shows two views of this cylinder at $100 x$ and at $500 x$. These photos show that the suiface is contaminated with smalf particles $1-10 \mu \mathrm{m}$ in size, whicl probably interfired with the surface-finish measurements. The areus between the particles, as may be seen in Fig. 8, appear very smooth. 
Another plastic cylinder was produced but it cracked after machining and therefore no surface finish measurement was made. In this case the plastic. polystyrene, was applied by dipping the copper mandrel several times in a diluce solution of polystyrene in toluene and drying in an oven between coats. Mictoscopic examination of the poiystyrene surface at $250 \mathrm{X}$ showed no surface features.

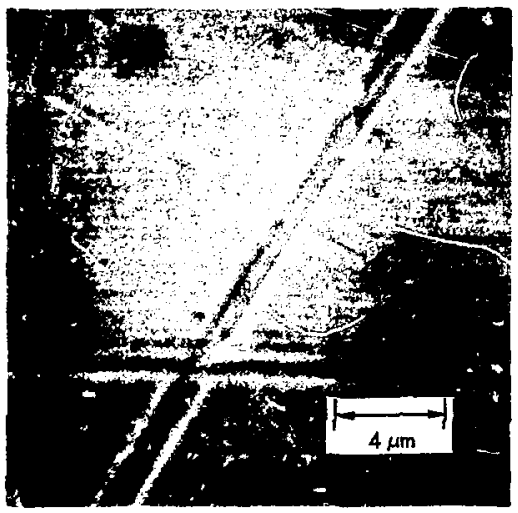

Fig. 7 Scanning electron microscope image of aluminum cylinder surface at $5000 \%$.
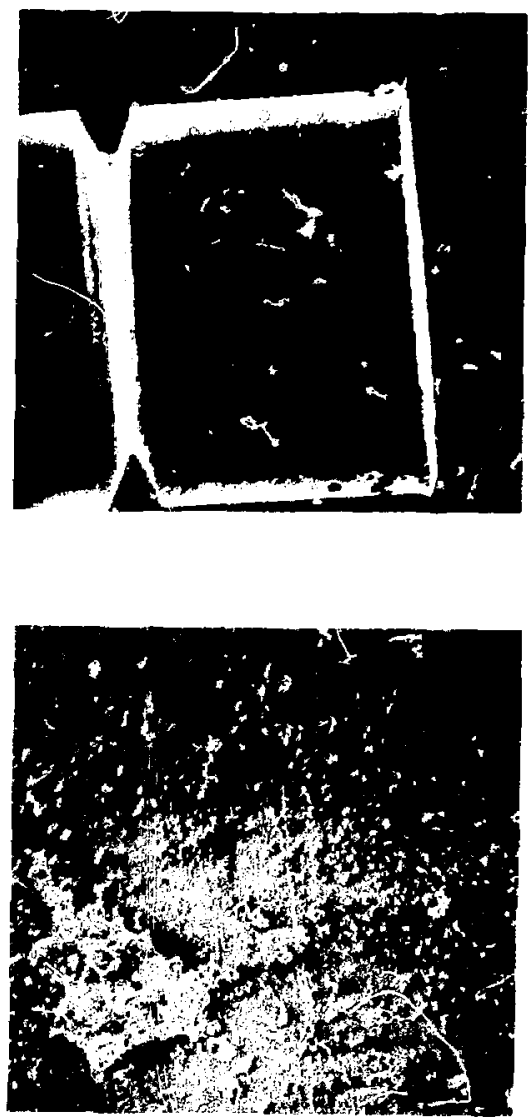

Fig. 8 scanning electron microscope imaze at $100 \times$ (1op) and $500 X$ of parylene cylinter after final machining and before dissol:ing away the copper mandrel. 


\section{Conclusions}

We have demonstrated that aluminum eylinders $500 \mu \mathrm{m}$ long and $500 \mu \mathrm{m}$ in diameter can be produced with surface finisnes of about $\pm 10 \mathrm{~nm}$. Several of these eylinders, with slight imperfections, sre available an.i could be used for atignment cylinders. We lave also demonstrated two nondestrustive methods oi" examining the surfaces of these cylinders before each laser shot, the TEM and the Taly-step. In addition, we have produced clear plastic cylirders of high surface quality but more work needs to be done on charatterizing these cylinders.

\section{Acknowledgments}

This project has drawn heavily from suveral moups here it LLI.. I would especially thank J. Bryan and j). Clouser of Metrology ior the dianiond turning, the Taiy-slep meisurements, and for suggesting tlie TEM mathod. Also, L. Clevenger for the aluminum vapor pluting. W. Steele for the SEM and S. Digiallonardo for the TEM work. 